\title{
BEST PROXIMITY POINTS FOR GENERALIZED MULTIVALUED CONTRACTIONS IN METRIC SPACES
}

\author{
ESMAEIL NAZARI \\ Received 15 September, 2014
}

\begin{abstract}
In the present paper, we prove a best proximity point theorem for multivalued nonself-contractive type mappings which is a generalization of recent best proximity point theorems and some famous fixed point theorems.
\end{abstract}

2010 Mathematics Subject Classification: 47H10; 47H06

Keywords: best proximity point, fixed point, optimal approximate solution, multivalued mapping

\section{INTRODUCTION}

Let $A, B$ be nonempty subsets of a metric space $(X, d)$ and $T: A \rightarrow B$ be a nonself-mapping. Clearly, the set of fixed points of $T$ can be empty. Therefore, it is of primary importance to seek an element $x$ that in some sense is closest to $T x$. That is, if there is no solution to the fixed point equation $T x=x$, one tries to determine an approximate solution $x$ subject to the condition that the distance between $x$ and $T x$ is minimal. A classical best approximation theorem was introduced by Fan [4]. It states that if $A$ is a non-empty compact convex subset of a Hausdorff locally convex topological vector space $X$ and $T: A \rightarrow X$ is a continuous mapping, Then there exists $x \in A$ such that $d(x, T x)=d(T x, A)$. Recently, there have been many subsequent extensions of Fan's theorem, see $[7,8,12]$ and references therein. A point $x \in A$ is called a best proximity point for $T$ if distance of $x$ to $T x$ is equal to the distance of $A$ to $B$. In fact best proximity point theorems have been studied to find necessary conditions such that the minimization problem,

$$
\min _{x \in A} d(x, T x)
$$

has at least one solution. Investigation of several variants of contractions for the existence of a best proximity point can be found in [2,3,5,9-11,13,14].

In this article, we consider a classes of multivalued non-self-mapping which called $(\phi, \theta)$ contractive mappings and we present some best proximity point theorems for these classes of non-self-mappings in metric spaces. 
Let $A$ and $B$ be two nonempty subsets of a metric space. We will use the following notations:

$$
\begin{gathered}
d(A, B)=\inf \{d(x, y): x \in A, y \in B\}, \\
A_{0}=\{x \in A: d(x, y)=d(A, B) \text { for some } y \in B\}, \\
B_{0}=\{y \in B: d(x, y)=d(A, B) \text { for some } y \in A\}, \\
D(x, B)=\inf \{d(x, y): y \in B\}, \quad \forall x \in X, \\
H(A, B)=\max \left\{\sup _{x \in A} D(x, B), \sup _{y \in B} D(y, A)\right\} .
\end{gathered}
$$

Let $A$ and $B$ be nonempty subsets of a metric space $(X, d)$. Assume that $T: A \rightarrow$ $2^{B}$ is a multivalued non-self-mapping. A point $x \in A$ is said to be a fixed point of $T$ if $x \in T x$. In case $A \cap B=\varnothing$, the multifunction $T$ has not fixed point. Then $D(x, T x)>0$ for all $x \in A$. Therefore, we can explore to find necessary conditions so that the minimization problem

$$
\min _{x \in A} D(x, T x)
$$

has at least one solution. Since $D(x, T x) \geq d(A, B)$ for all $x \in A$, the optimal solution to the problem (1.2) is obtained in some points of $A$ for which the value $d(A, B)$ is attained. A point $x \in A$ is called a best proximity point of a multivalued non-selfmapping $T$, if $D(x, T x)=d(A, B)$. We note that if $d(A, B)=0$, then we get a fixed point of $T$.

Definition 1 ([11]). Let $(A, B)$ be a pair of nonempty subsets of a metric space $(X, d)$ with $A_{0} \neq \varnothing$. Then the pair $(A, B)$ is said to have the $P$-property iff

$$
\left\{\begin{array}{l}
d\left(x_{1}, y_{1}\right)=d(A, B) \\
d\left(x_{2}, y_{2}\right)=d(A, B)
\end{array} \quad \Rightarrow d\left(x_{1}, x_{2}\right)=d\left(y_{1}, y_{2}\right),\right.
$$

where $x_{1}, x_{2} \in A$ and $y_{1}, y_{2} \in B$

Definition 2 ([15]). Let $(A, B)$ be a pair of nonempty subsets of a metric space $(X, d)$ with $A_{0} \neq \varnothing$. Then the pair $(A, B)$ is said to have the weak $P$-property iff

$$
\left\{\begin{array}{l}
d\left(x_{1}, y_{1}\right)=d(A, B) \\
d\left(x_{2}, y_{2}\right)=d(A, B)
\end{array} \quad \Rightarrow d\left(x_{1}, x_{2}\right) \leq d\left(y_{1}, y_{2}\right),\right.
$$

where $x_{1}, x_{2} \in A$ and $y_{1}, y_{2} \in B$.

Definition 3. We say that $\varphi:[0, \infty[\rightarrow[0, \infty[$ is a (c)-comparison function if and only if the following conditions hold:

(i) $\varphi$ is a nondecreasing function,

(ii) for any $t>0, \sum_{n=0}^{\infty} \varphi^{n}(t)$ is a convergent series. 
In what follows, we will denote:

$$
\Theta=\left\{\theta:[0,+\infty)^{4} \rightarrow[0,+\infty):\right.
$$

$\theta$ is continuous and $\left.\theta\left(t_{1}, t_{2}, t_{3}, t_{4}\right)=0 \Leftrightarrow t_{1} t_{2} t_{3} t_{4}=0\right\}$.

Example 1. The following functions belong to $\Theta$ :

(1) $\theta\left(t_{1}, t_{2}, t_{3}, t_{4}\right)=L \min \left\{t_{1}, t_{2}, t_{3}, t_{4}\right\}, L>0$

(2) $\theta\left(t_{1}, t_{2}, t_{3}, t_{4}\right)=t_{1} t_{2} t_{3} t_{4}$

(3) $\theta\left(t_{1}, t_{2}, t_{3}, t_{4}\right)=\ln \left(1+t_{1} t_{2} t_{3} t_{4}\right)$,

(4) $\theta\left(t_{1}, t_{2}, t_{3}, t_{4}\right)=\exp \left(t_{1} t_{2} t_{3} t_{4}\right)-1$.

The notion of almost $(\varphi, \theta)$-contraction for single valued non-self mapping was introduced by Bessem Samet as follows.

Definition 4 ([10]). A mapping $T: A \rightarrow B$ is said to be an almost $(\varphi, \theta)$-contraction if and only if there exist $\varphi \in \Phi$ and $\theta \in \Theta$ such that, for all $x, y \in A$,

$$
\begin{aligned}
d(T x, T y) & \leq \varphi(d(x, y))+\theta(d(y, T x)-d(A, B), d(x, T y) \\
& -d(A, B), d(x, T x)-d(A, B), d(y, T y)-d(A, B))
\end{aligned}
$$

He proved the following result.

Theorem 1 ([10]). Let $A$ and $B$ be closed subsets of a complete metric space $(X, d)$ such that $A_{0}$ is nonempty. Suppose that $T: A \rightarrow B$ satisfies the following conditions:

(i) $T$ is an almost $(\varphi, \theta)$-contraction,

(ii) $T\left(A_{0}\right) \subseteq B_{0}$,

(iii) the pair $(A, B)$ has the $P$-property.

Then, there exists a unique element $x^{*} \in A$ such that

$$
d\left(x^{*}, T x^{*}\right)=d(A, B)
$$

Moreover, for any fixed element $x_{0} \in A_{0}$, any iterative sequence $\left\{x_{n}\right\}$ satisfying

$$
d\left(x_{n+1}, T x_{n}\right)=d(A, B)
$$

converges to $x^{*}$.

Now, in the following we defined the notion of $(\varphi, \theta)$ - contraction for multivalued mappings. 
Definition 5. A mapping $T: A \rightarrow 2^{B}$ is said to be an almost $(\varphi, \theta)$-contraction if and only if there exist $\varphi \in \Phi$ and $\theta \in \Theta$ such that, for all $x, y \in A$,

$$
\begin{aligned}
H(T x, T y) & \leq \varphi(d(x, y))+\theta(D(y, T x)-d(A, B), D(x, T y) \\
& -d(A, B), D(x, T x)-d(A, B), D(y, T y)-d(A, B))
\end{aligned}
$$

\section{MAIN RESUltS}

Our first main result is the following theorem.

Theorem 2. Let $A$ and $B$ be closed subsets of a complete metric space $(X, d)$ such that $A_{0} \neq \varnothing$ and the pair $(A, B)$ satisfies the weak P-property. Suppose that $T: A \rightarrow 2^{B}$ be a multi-valued almost $(\varphi, \theta)$-contraction non-self mapping. If $T(x)$ is bounded and closed in $B$ for all $x \in A$, and $T\left(x_{0}\right) \subseteq B_{0}$ for each $x_{0} \in A_{0}$, then $T$ has a best proximity point in $A$.

Proof. Select $x_{0} \in A_{0}$ and $y_{0} \in T x_{0} \subseteq B_{0}$. By the definition of the set $B_{0}$, we can fined an element $x_{1}$ in $A_{0}$ such that $d\left(x_{1}, y_{0}\right)=d(A, B)$. If $y_{0} \in T x_{1}$, then $d(A, B) \leq D\left(x_{1}, T x_{1}\right) \leq d\left(x_{1}, y_{0}\right)=d(A, B)$, therefore $D\left(x_{1}, T x_{1}\right)=d(A, B)$ and $x_{1}$ is a best proximity point of $T$. If $y_{0} \notin T x_{1}$ and $q>1$ be given. Then

$$
0<d\left(y_{0}, T x_{1}\right) \leq H\left(T x_{0}, T x_{1}\right)<q H\left(T x_{0}, T x_{1}\right) .
$$

Hence, there exists $y_{1} \in T x_{1}$ such that

$$
\begin{array}{r}
0<d\left(y_{0}, y_{1}\right)<q H\left(T x_{0}, T x_{1}\right) \leq q \varphi\left(d\left(x_{0}, x_{1}\right)\right)+q \theta\left(D\left(x_{1}, T x_{0}\right)-d(A, B),\right. \\
\left.D\left(x_{0}, T x_{1}\right)-d(A, B), D\left(x_{0}, T x_{0}\right)-d(A, B), D\left(x_{1}, T x_{1}\right)-d(A, B)\right)
\end{array}
$$

Since $D\left(x_{1}, T x_{0}\right)=d(A, B)$, we have

$$
\begin{aligned}
0<d\left(y_{0}, y_{1}\right) & <q \varphi\left(d\left(x_{0}, x_{1}\right)\right)+q \theta\left(0, D\left(x_{0}, T x_{1}\right)-d(A, B),\right. \\
& \left.D\left(x_{0}, T x_{0}\right)-d(A, B), D\left(x_{1}, T x_{1}\right)-d(A, B)\right) \\
& =q \varphi\left(d\left(x_{0}, x_{1}\right)\right) .
\end{aligned}
$$

One the other hand since $y_{1} \in T x_{1} \subseteq B_{0}$, there exists $x_{2} \in A_{0}$ such that $d\left(x_{2}, y_{1}\right)=$ $d(A, B)$. By using the weak P-property of $(A, B)$ we obtain $d\left(x_{2}, x_{1}\right) \leq d\left(y_{0}, y_{1}\right)$. Now, put $t_{0}=d\left(x_{0}, x_{1}\right)$, then $t_{0}>0$ and by (2.1) we have $d\left(x_{1}, x_{2}\right)<q \varphi\left(t_{0}\right)$. Since $\varphi$ is strictly increasing, $\varphi\left(d\left(x_{1}, x_{2}\right)\right)<\varphi\left(q \varphi\left(t_{0}\right)\right)$. Set $q_{1}=\frac{\varphi\left(q \varphi\left(t_{0}\right)\right)}{\varphi\left(d\left(x_{1}, x_{2}\right)\right)}>1$. If $y_{1} \in T x_{2}$ then $x_{2}$ is a best proximity point of $T$. suppose that $y_{1} \notin T x_{2}$, then

$$
0<d\left(y_{1}, T x_{2}\right) \leq H\left(T x_{1}, T x_{2}\right)<q H\left(T x_{1}, T x_{2}\right) .
$$


Therefore, there exits $y_{2} \in T x_{2}$ such that

$$
\begin{aligned}
0<d\left(y_{2}, y_{1}\right) & <q_{1} H\left(T x_{2}, T x_{1}\right) \\
& \leq q_{1} \varphi\left(d\left(x_{1}, x_{2}\right)\right)+q_{1} \theta\left(D\left(x_{2}, T x_{1}\right)-d(A, B), D\left(x_{1}, T x_{2}\right)\right. \\
& \left.-d(A, B), D\left(x_{1}, T x_{1}\right)-d(A, B), D\left(x_{2}, T x_{2}\right)-d(A, B)\right)
\end{aligned}
$$

Since $D\left(x_{2}, T x_{1}\right)=d(A, B)$, we have

$$
\begin{aligned}
0<d\left(y_{2}, y_{1}\right) & <q_{1} \varphi\left(d\left(x_{1}, x_{2}\right)\right)+q_{1} \theta\left(0, D\left(x_{1}, T x_{2}\right)-d(A, B), D\left(x_{1}, T x_{1}\right)\right. \\
& \left.-d(A, B), D\left(x_{2}, T x_{2}\right)-d(A, B)\right) \\
& =q_{1} \varphi\left(d\left(x_{1}, x_{2}\right)\right)=\varphi\left(q \varphi\left(t_{0}\right)\right) .
\end{aligned}
$$

Again, since $y_{2} \in T x_{2} \subseteq B_{0}$, there exist $x_{3} \in A_{0}$ such that $d\left(x_{3}, y_{2}\right)=d(A, B)$. By using the weak P-property of $(A, B)$ we obtain $d\left(x_{3}, x_{2}\right) \leq d\left(y_{2}, y_{1}\right)$. Since $\varphi$ is in strictly increasing by using (2.2) we have $\varphi\left(d\left(x_{3}, x_{2}\right)\right)<\varphi^{2}\left(q \varphi\left(t_{0}\right)\right)$. Set $q_{2}=\frac{\varphi^{2}\left(q \varphi\left(t_{0}\right)\right)}{\varphi\left(d\left(x_{3}, x_{2}\right)\right)}>1$. If $y_{2} \in T x_{3}$ then $x_{3}$ is a best proximity point of $T$. Suppose that $y_{2} \notin T x_{3}$ then we have,

$$
0<d\left(y_{2}, T x_{3}\right) \leq H\left(T x_{2}, T x_{3}\right)<q_{2} H\left(T x_{2}, T x_{3}\right) .
$$

Then there is $y_{3} \in T x_{3}$ such that

$$
\begin{aligned}
0<d\left(y_{3}, y_{2}\right) & <q_{2} H\left(T x_{3}, T x_{2}\right) \leq q_{2} \varphi\left(d\left(x_{3}, x_{2}\right)\right) \\
& +q_{2} \theta\left(D\left(x_{3}, T x_{2}\right)-d(A, B), d\left(x_{2}, T x_{3}\right)-d(A, B), D\left(x_{3}, T x_{3}\right)\right. \\
& \left.-d(A, B), D\left(x_{2}, T x_{2}\right)-d(A, B)\right)
\end{aligned}
$$

Since $D\left(x_{3}, T x_{2}\right)=d(A, B)$ we have

$$
\begin{aligned}
0<d\left(y_{3}, y_{2}\right) & <\varphi\left(d\left(x_{3}, x_{2}\right)\right)+q_{2} \theta\left(0, d\left(x_{2}, T x_{3}\right)-d(A, B), D\left(x_{3}, T x_{3}\right)\right. \\
& \left.-d(A, B), D\left(x_{2}, T x_{2}\right)-d(A, B)\right) \\
& =q_{2} \varphi\left(d\left(x_{3}, x_{2}\right)\right)=\varphi^{2}\left(q \varphi\left(t_{0}\right)\right)
\end{aligned}
$$

By continuing this process, for each $n \in N$, we can find a sequences $\left\{x_{n}\right\}$ and $\left\{y_{n}\right\}$ in $A_{0}$ and $B_{0}$ respectively, such that,

(1) $y_{n} \in T x_{n} \subseteq B_{0}$,

(2) $d\left(x_{n+1}, y_{n}\right)=d(A, B)$ 
(3) $d\left(y_{n+1}, y_{n}\right) \leq \varphi^{n}\left(q \varphi\left(t_{0}\right)\right)$.

Since $(A, B)$ satisfies the weak p-property, we conclude that

$$
d\left(x_{n}, x_{n+1}\right) \leq d\left(y_{n-1}, y_{n}\right) \quad \forall n \in N
$$

we now have

$$
d\left(x_{n}, x_{n+1}\right) \leq d\left(y_{n-1}, y_{n}\right) \leq \varphi^{n-1}\left(q \varphi\left(t_{0}\right)\right.
$$

Let $m>n$. Then

$$
d\left(x_{n}, x_{m}\right) \leq \sum_{i=n}^{m-1} d\left(x_{i}, x_{i+1}\right) \leq \sum_{i=n}^{m-1} \varphi^{i-1}\left(q \varphi\left(t_{0}\right)\right)
$$

and so $\left\{x_{n}\right\}$ is a Cauchy sequence in $A$. Hence, there exists $x^{*} \in A$ such that $x_{n} \rightarrow x^{*}$. Similarly, by using (3) we can show that the sequence $\left\{y_{n}\right\}$ in $B$ is Cauchy and hence is convergent. Suppose that $y_{n} \rightarrow y^{*}$. By the relation $d\left(x_{n+1}, y_{n}\right)=d(A, B)$, for all $n \in N$, we conclude that $d\left(x^{*}, y^{*}\right)=d(A, B)$. Now we show that $y^{*} \in T x^{*}$. Since $y_{n} \in T x_{n}$, we obtain

$$
\begin{aligned}
& \lim _{n \rightarrow \infty} D\left(y_{n}, T x^{*}\right) \\
& \leq \lim _{n \rightarrow \infty} H\left(T x_{n}, T x^{*}\right) \\
& \leq \lim _{n \rightarrow \infty}\left[\varphi\left(d\left(x_{n}, x^{*}\right)\right)+\theta\left(D\left(x^{*}, T x_{n}\right)\right.\right. \\
&- d(A, B), D\left(x_{n}, T x^{*}\right)-d(A, B), D\left(x_{n}, T x_{n}\right)-d(A, B), \\
&\left.\left.D\left(x^{*}, T x^{*}\right)-d(A, B)\right)\right] \\
&=0+\theta\left(\lim _{n \rightarrow \infty} d\left(x^{*}, y_{n}\right)-d(A, B), \lim _{n \rightarrow \infty}\left(D\left(x_{n}, T x^{*}\right)\right.\right. \\
&\left.-d(A, B)), \lim _{n \rightarrow \infty}\left(D\left(x_{n}, T x_{n}\right)-d(A, B)\right), D\left(x^{*}, T x^{*}\right)-d(A, B)\right) \\
&=0+\theta\left(0, \lim _{n \rightarrow \infty}\left(D\left(x_{n}, T x^{*}\right)\right.\right. \\
&\left.-d(A, B)), \lim _{n \rightarrow \infty}\left(D\left(x_{n}, T x_{n}\right)-d(A, B)\right), D\left(x^{*}, T x^{*}\right)-d(A, B)\right) \\
&=0 .
\end{aligned}
$$

Thus, we have

$$
\lim _{n \rightarrow \infty} D\left(y_{n}, T x^{*}\right)=0 .
$$

Hence $D\left(y^{*}, T x^{*}\right)=0$. Since $T x^{*}$ is closed, We conclude that $y^{*} \in T x^{*}$. Now we have,

$$
d(A, B) \leq D\left(x^{*}, T x^{*}\right) \leq d\left(x^{*}, y^{*}\right)=d(A, B),
$$

which implies that $D\left(x^{*}, T x^{*}\right)=d(A, B)$, that is $x^{*} \in A$ is a best proximity point of $T$. This completes the proof of theorem. 
Taking $\varphi(t)=\alpha t$ we have the following result which an extension of theorem 2.1 in [1].

Corollary 1. Let $(A, B)$ be a pair of nonempty closed subsets of a complete metric space $(X, d)$ such that $A_{0} \neq \varnothing$ and $(A, B)$ satisfies the weak $P$-property. Let $T: A \rightarrow$ $2^{B}$ be a multivalued non-self-mapping, for which there exist a constant $\alpha \in[0,1)$ and $\theta \in \Theta$ such that for all $x, y \in X$

$$
\begin{aligned}
H(T x, T y) & \leq \alpha d(x, y)+\theta(D(y, T x)-d(A, B), D(x, T y) \\
& -d(A, B), D(x, T x)-d(A, B), D(y, T y)-d(A, B))
\end{aligned}
$$

Suppose also that $T(x)$ is bounded and closed in $B$ for all $x \in A$, and $T\left(x_{0}\right) \subseteq B_{0}$ for each $x_{0} \in A_{0}$, then $T$ has a best proximity point in $A$.

Example 2. Let $X=\Re$ with the usual metric. Suppose $A:=\{0,3,6,9\}$ and $B:=$ $\{-1,2,5,8\}$. Then, $A$ and $B$ are nonempty and closed subsets of $X$ and $A_{0}=A$ and $B_{0}=B$. We note that, $d(A, B)=1$. It is easy to show that the pair $(A, B)$ has the weak $P$-property. Let $T: A \rightarrow 2^{B}$ ba a mapping defined by $T 0=\{8\}$ and $T x=\{5,8\}$, if $x \neq 0$. Consider the functions $\theta\left(t_{1}, t_{2}, t_{3}, t_{4}\right)=t_{1} t_{2} t_{3} t_{4}$ and $\varphi(t)=\frac{t}{2}$ for all $t \geq 0$. Then $T$ is $(\varphi, \theta)$ - multivalued contraction. Thus $T$ has a best proximity point Note that $x=6$ and $x=9$ are best proximity point of $T$. It is interesting to note that the non-self mapping $\mathrm{T}$ is not a non-self contraction.

Taking $B=A$ in Theorem 2, we obtain the following result.

Corollary 2. Let $(X, d)$ be a complete metric space, and $A$ be a nonempty and closed subset of $X$. Let $T: A \rightarrow 2^{A}$ be an almost $(\varphi, \theta)$-contraction self-mapping. Then $T$ has a fixed point $x \in A$.

Taking $\varphi(t)=\alpha t$ and $\theta\left(t_{1}, t_{2}, t_{3}, t_{4}\right)=L \min \left\{t_{1}, t_{2}, t_{3}, t_{4}\right\}$, we obtain from Corollary 2 the following result which is a generalization of Nadler fixed point theorem [6].

Corollary 3. Let $(X, d)$ be a complete metric space, and A be a nonempty closed subset of $X$. Let $T: A \rightarrow 2^{A}$ be a mapping such that there exist $\alpha \in[0,1)$ and $L>0$ such that, for all $x, y \in A$,

$$
H(T x, T y) \leq \alpha d(x, y)+L \min \{D(y, T x), D(x, T y), D(x, T x), D(y, T y)\}
$$

Then $T$ has a unique fixed point $x \in A$.

\section{ACKNOWLEDGEMENT}

The authors are grateful to the referees for their helpful suggestions contributing to the improvement of the paper. 


\section{REFERENCES}

[1] A. Abkar and M. Gabeleh, "The existence of best proximity points for multivalued nonselfmappings," RACSAM, vol. 107, no. 2, pp. 319-325, 2013, doi: 10.1007/s13398-012-0074-6.

[2] A. Abkar and M. Gabeleh, "A note on some best proximity point theorems proved under pproperty," abstract Appl. Anal, vol. Article ID 189567, 2013.

[3] A. A. Eldred and P. Veeramani, "Existence and convergence of best proximity points," J. Math. Anal. Appl, vol. 323, no. 2, pp. 1001-1006, 2006, doi: 10.1016/j.jmaa.2005.10.081.

[4] K. Fan, "Extensions of two fixed point theorems of F.E. Browder," Math. Z, vol. 112, no. 3, pp. 234-240, 1969.

[5] W. A. Kirk, S. Reich, and P. Veeramani, "Proximinal retracts and best proximity pair theorems," Numer. Funct. Anal. Optim, vol. 24, no. 7-8, pp. 851-862, 2003, doi: 10.1081/NFA-120026380.

[6] S. B. J. Nadler, "Multivalued contraction mappinsg," Pac. J. Math, vol. 30, no. 2, pp. 475-488, 1969, doi: 10.2140/pjm.1969.30.475.

[7] J. B. Prolla, "Fixed point theorems for set valued mappings and existence of best approximations," Numer. Funct. Anal. Optim., vol. 5, no. 4, pp. 449-455, 2010.

[8] S. Reich, "Approximate selections, best approximations, fixed points and invariant sets," J.Math. Anal. Appl, vol. 62, no. 1, pp. 104-113, 1978, doi: 10.1016/0022-247X(78)90222-6.

[9] S. Sadiq Basha, "Extensions of banach-s contraction principle," Numer. Funct. Anal. Optim, vol. 31, no. 5, pp. 569-576, 2010, doi: 10.1080/01630563.2010.485713.

[10] B. Samet, "Some results on best proximity points," J. Optim. Theory Appl., vol. 159, no. 1, pp. 281-291, 2013, doi: 10.1007/s10957-013-0269-9.

[11] V. Sankar Raj, "A best proximity point theorem for weakly contractive non-self-mappings," Nonlinear Anal., vol. 74, no. 14, pp. 4804-4808, 2011, doi: 10.1016/j.na.2011.04.052.

[12] V. M. Seghal and S. P. Singh, "A generalization of multifunctions of Fans best approximation theorem," Proc. Amer.Math. Soc, vol. 102, no. 3, pp. 534-537, 1988.

[13] N. Shahzad, S. Sadiq Basha, and R. Jeyaraj, "Common best proximity points: global optimal solutions," J. Optim. Theory Appl, vol. 148, no. 148, pp. 69-78, 2011, doi: 10.1007/s10957-0109745-7.

[14] T. Suzuki, M. Kikkawa, and C. Vetro, "The existence of best proximity points in metric spaces with the property UC," Nonlinear Anal., vol. 71, no. 7, pp. 2918-2926, 2009, doi: 10.1016/j.na.2009.01.173.

[15] J. Zhang, Y. Su, and Q. Cheng, "A note on a best proximity point theorem for Geraghtycontractions," Fixed Point Theory and Applications, vol. article 83, 2013, doi: 10.1186/16871812-2013-83.

Author's address

Esmaeil Nazari

Department of Mathematics, Tafresh University, Tafresh, Iran

E-mail address: nazari.esmaeil@gmail.com 